\title{
A normatividade do discurso em Habermas Sobre a neutralidade do principio do discurso em relação ao direito e à moral
}

Luiz Repa

UFPR

luizrepa@uol.com.br

resumo 0 objetivo desse artigo é examinar o sentido da neutralidade do princípio do discurso na teoria habermasiana do direito e da democracia. Em relação ao direito e à moral, 0 princípio do discurso é neutro, porém contém uma normatividade que se baseia no conteúdo dos pressupostos pragmáticos da argumentação em geral. Ao contrário de algumas interpretações que imputam um sentido moral mínimo ao princípio do discurso, pretende-se mostrar como a teoria habermasiana pode conferir formas distintas de aplicação a este princípio, conforme as questões práticas que surgem na esfera pública política.

palavras-chave Habermas; direito; moral; democracia; neutralidade do princípio do discurso; imparcialidade

Uma das teses mais controversas da teoria do direito e da democracia de Habermas consiste na afirmação de que o princípio do discurso seria normativamente neutro em relação tanto à moral quanto ao direito. Dada essa neutralidade, ele poderia ser especificado, de um lado, como princípio moral para a resolução argumentativa de conflitos em torno de normas morais, e assumiria a forma de um princípio de universalização (U), capaz de testar quais normas são universalizáveis e, dessa maneira, aceitáveis por todos os possíveis destinatários. De outro lado, ele se converteria em um princípio de democracia para a legitimação de normas jurídicas em processos de positivação do direito. Nesse caso só seriam legítimas normas jurídicas que pudessem contar com o assentimento de todos os parceiros de direito. Nele mesmo, o princípio do 
discurso (D) estabelece que "são válidas somente as normas de ação com as quais todos os possíveis atingidos podem assentir enquanto participantes de discursos racionais" (HABERMAS, 1994, p. 138). O princípio do discurso se coloca, assim, em um plano a tal ponto abstrato que permanece indeterminada a natureza das normas de ação em questão, bem como o conjunto dos atingidos por elas, e ainda as formas particulares de discurso racional. Todas as determinações dessas variáveis corresponderiam a especificações distintas do princípio do discurso. $\mathrm{Ou}$ seja, embora contenha claramente um conteúdo normativo, o princípio do discurso não equivaleria a um princípio moral primordial, em referência ao qual se poderia fundar ou pelo menos medir a legitimidade do direito positivo.

É justamente em relação a essa diferença com a moral que a tese da neutralidade parece ser bastante problemática. De fato, não se pode evitar a surpresa para com ela, na medida em que aquele conteúdo normativo explicita, nas palavras de Habermas, "o sentido da imparcialidade dos juízos práticos” (HABERMAS, 1994, p. 138). Se é assim, parece difícil discordar, por exemplo, de Karl-Otto Apel, quando objeta que não vê “como se poderia negar a propriedade moral do 'conteúdo normativo' do princípio da 'imparcialidade de juízos práticos', que se exprime no princípio do discurso" (APEL, 1998, p. 761). Ou seja, parece impossível perceber exatamente em que tal imparcialidade difere daquela de um princípio moral exigindo a consideração simétrica de todos os interesses envolvidos. Como tal normatividade do discurso poderia ser não-moral, no sentido de sua suposta neutralidade abstrata? Em que sentido deve-se entender a "imparcialidade" de juízos práticos, explicitadas pelo princípio D?

Para tratar dessa questão, certamente incômoda, deixarei de lado uma perspectiva evolutiva sobre o pensamento de Habermas a respeito do papel da moral no interior de sua teoria do discurso. Isto é, deixarei de lado as transformações gradativas que se operaram desde as primeiras formulações sobre a ética do discurso. Tampouco tratarei de reconstruir o debate de Habermas com Apel, no qual essas transformações são manifestadas de maneira mais clara, apesar de a própria questão sobre a normatividade neutra do discurso ser tratada mais diretamente em uma réplica a Apel (cf. HABERMAS, 2005). A seguir vou me limitar, primeiramente, a lembrar os motivos mais substantivos da teoria discursiva do direito às 
quais se liga a tese da neutralidade. Em seguida, tentarei reconstituir a teoria habermasiana do discurso, para num passo subseqüente poder distinguir a normatividade discursiva da normatividade moral. Com as distinções alcançadas nessa etapa, procurarei por fim delimitar o sentido do conteúdo normativo de $\mathrm{D}$ em sua relação com as diversas formas de discurso, pressupostas pelo princípio da democracia.

\section{I}

Começo então pelas as razões que levam Habermas a estabelecer, no interior de sua filosofia do direito, a neutralidade normativa do princípio $\mathrm{D}$ em relação à moral e ao direito.

Em primeiro lugar, se o princípio do discurso fosse de antemão determinado como princípio moral, seu uso como forma de legitimação do direito positivo teria como preço uma subordinação hierárquica deste à moral, semelhante àquela realizada pela tradição do direito natural em sua vertente liberal, na qual Locke se destacaria de maneira paradigmática. Uma subordinação ou hierarquia de normas é vista por Habermas como pertencente ao "mundo do direito pré-moderno" (HABERMAS, 1994, p. 153), ainda que evidentemente uma moral universalista desligada da religião, completamente racionalizada e pós-tradicional, não lhe fosse conhecida. Pode-se dizer, então, que tal idéia de hierarquia seria um resquício pré-moderno em um estágio de fundamentação de normas pós-tradicional. Em contraste com tal hierarquia, Habermas propõe uma relação de complementação entre direito e moral.

Por outro lado, a subordinação do direito à moral não seria "compatível com a idéia de uma autonomia realizada no medium do próprio direito" (HABERMAS, 1994, p. 157). Ou seja, ela não é compatível com a autonomia política dos cidadãos, que confere legitimidade ao processo de legislação na medida em que eles se podem ver como autores das leis, às quais se submetem enquanto destinatários delas. Para fazer jus à prática de autonomia política, é preciso renunciar à idéia de direitos fundamentados moralmente que apenas esperam por sua positivação jurídica, determinando previamente o legislador político. "A idéia de autolegislação de cidadãos não pode ser reduzida à autolegislação moral 


\section{2}

de pessoas singulares. A autonomia precisa ser concebida de maneira mais universal e neutra. Por isso introduzi um princípio do discurso que é de início indiferente em relação à moral e ao direito. O princípio do discurso deve assumir primeiramente, pela via da institucionalização jurídica, a figura de um princípio da democracia que confere em seguida, por sua vez, força geradora de legitimidade ao processo de positivação do direito" (HABERMAS, 1994, p. 158).

Somente o princípio da democracia pode criar legitimidade, mas isso de maneira tal que os direitos subjetivos que garantem a autonomia privada, cuja substância é própria dos direitos humanos fundamentados moralmente, constituem-se como condições formais de possibilidade da autonomia pública. Desse modo, eles não são restrições às deliberações do legislador político, mas antes condições que as possibilitam, sendo eles mesmos, ao mesmo tempo, conteúdo de normas jurídicas a serem positivadas no processo legislativo. Nisso reside a idéia central de co-originariedade de autonomia privada e autonomia pública, direitos humanos e soberania popular.

Por fim, um sobrepeso moral no interior do próprio processo de deliberação democrático, caso o princípio da democracia fosse apenas uma configuração secundária de um princípio de teor moral, teria por resultado uma redução da complexidade do processo político de formação da vontade tomado em sua concretude. Pois nele se dão não só conflitos sobre a moralidade de determinadas normas jurídicas, mas também conflitos de natureza ética a respeito da identidade coletiva ou concepções de bem viver próprias de uma comunidade política histórica e particular. Somam-se a isso conflitos de natureza pragmática a respeito dos melhores meios para a realização de fins comuns, para não mencionar negociações para a formação de compromissos que compensem interesses não generalizáveis. "A necessidade de regulamentação não se esgota em situações problemáticas que exigem um uso moral da razão prática. $\mathrm{O}$ medium direito é solicitado justamente também para situações problemáticas que requerem a persecução cooperativa de fins coletivos e o asseguramento de bens coletivos. Os discursos de fundamentação e de aplicação [das normas jurídicas] precisam se abrir por isso também para o uso pragmático e sobretudo para o uso ético-político da razão prática" (HABERMAS, 1994, p. 191). 
Dessa maneira, o direito e a política abarcam uma série de formas discursivas diferenciadas (discursos moral, ético-político e pragmático ${ }^{1}$, além de negociações reguladas por procedimentos), que penetram e sustentam a fundamentação e a aplicação de normas jurídicas. Essa diferenciação discursiva só é possível porque o princípio D é neutro, permitindo especificações distintas conforme os tipos de questionamentos levantados na esfera pública. Ou seja, o princípio D não só se converte no princípio da democracia ao lidar com normas jurídicas, mas também se especifica e operaliza para os diversos tipos de questionamento que são abarcados por tais normas.

Em suma, a neutralidade ou indiferença do princípio D é fundamental para evitar a subordinação do direito à moral, a qual é vista, por um lado, como resquício pré-moderno, e, por outro, como limitação indevida da autonomia política, e para evitar uma redução da complexidade do processo político-jurídico. No entanto é evidente que esses motivos da filosofia do direito não podem fundamentar por si mesmos tal neutralidade. Ela só pode ser sustentada no interior de uma teoria do discurso em geral.

Até aqui nos referimos à diferenciação do discurso conforme questões práticas, isto é, às formas distintas de argumentação moral, ético-política e pragmática nas quais o princípio D se configura de maneira diferente, conforme o tipo de questionamento. No entanto, esses discursos constituem formas de argumentação entre outras, pois, conforme a abordagem dada na Teoria da ação comunicativa, procedimentos argumentativos se verificam para a resolução de questões teórico-científicas, mas também estéticas, terapêuticas, gramaticais e hermenêuticas, ou seja, questões que não são, em primeira linha, práticas.

O princípio D se baseia no conteúdo normativo dos pressupostos pragmáticos da argumentação em geral, ainda que ele seja talhado para questões práticas, isto é, para a justificação de normas de ação, sejam elas quais forem. O princípio D é dessa maneira, como veremos a seguir, um aproveitamento do conteúdo normativo dos discursos em geral para a constituição de um ponto de vista imparcial próprio dos juízos práticos. Portanto, para a 


\section{4}

compreensão da neutralidade normativa de $\mathrm{D}$, torna-se decisivo a correta interpretação desse conteúdo normativo embutido em todo discurso racional e como ele se desenvolve nas diversas formas de discurso.

Convém lembrar inicialmente que Habermas considera o discurso a "forma reflexiva" da ação comunicativa, isto é, de um tipo de interação social em que o meio de coordenar os diversos planos de ação dos agentes sociais envolvido é dado na forma de um acordo racional, do entendimento recíproco entre as partes, alcançado através da linguagem. O processo comunicativo se refere a um determinado uso da linguagem, orientado para a obtenção de um acordo, de modo tal que os falantes têm de restringir seus planos de ação individuais às condições necessárias para o entendimento mútuo.

O ponto de partida reconstrutivo de Habermas consiste, então, na idéia de que todo participante de uma ação orientada ao entendimento intersubjetivo sobre algo no mundo tem de levantar em cada ato de fala pelo menos quatro pretensões de validade e supor que cada uma delas possa ser resgatada (cf. HABERMAS, 1995c). Geralmente pressuposto na práxis comunicativa cotidiana, o reconhecimento dessas quatro pretensões universais de validade forma um consenso de fundo para os processos de entendimento recíproco. Assim, para que estes possam se desenvolver de maneira não-perturbada, é preciso, em termos ideais, que os participantes da interação reivindiquem e aceitem mutuamente, para seus atos de fala, a inteligibilidade das orações que os constitui, a verdade do seu conteúdo proposicional, a correção normativa do proferimento em relação a um contexto de normas compartilhado e, finalmente, a veracidade com que cada um expressa suas intenções. Essas três últimas pretensões - de verdade, correção, e veracidade - referem-se, de maneira constitutiva, a três conceitos formais de mundo, respectivamente: ao mundo objetivo enquanto totalidade dos fatos, dos estados de coisas existentes, ao mundo social enquanto totalidade das relações interpessoais de um grupo social, reguladas de uma maneira supostamente legítima, e ao mundo subjetivo de cada um enquanto totalidade das vivências a que cada um tem um acesso privilegiado.

$\mathrm{Na}$ medida em que a comunicação é perturbada, o consenso de fundo pode ser questionado sob cada um desses aspectos de validade. Pode-se, nesse caso, pôr em questão a inteligibilidade das orações, a verdade do 
enunciado, a justeza normativa do proferimento e a veracidade das intenções expressas do falante. No primeiro caso, duvida-se de que as orações tenham sido geradas conforme as regras lingüísticas; no segundo caso, duvida-se de que se cumpram as condições de validade do enunciado, isto é, que estados de coisas ou as pressuposições de existência de seu conteúdo proposicional sejam reais; no terceiro caso, duvida-se de que seja legítimo o contexto normativo a que se refere o ato de fala; no quarto caso, duvida-se da sinceridade do falante ou supõe-se que ele se engane a si mesmo. Igualmente, pode-se responder a esses questionamentos típicos com as seguintes construções discursivas: respectivamente, explicações lingüísticas a respeito da boa ou má conformação do construto simbólico, ou também interpretações hermenêuticas sobre o sentido dos símbolos; asserções e explicações sobre as condições de validade do enunciado; justificações sobre normas e, por fim, interrogações ou mesmo uma análise terapêutica. Soma-se a isso ainda a possibilidade de resgatar uma pretensão de validade que não é universal mas recorrente na práxis comunicativa, a qual diz respeito à adequação a determinados padrões valorativos ou a autenticidade de uma manifestação estética. Nesse caso, também é possível encetar uma discussão correspondente.

Nesse nível já começa, portanto, a se instaurar uma respectiva forma de argumentação. A remissão aos procedimentos argumentativos é imanente à ação orientada ao entendimento, já que o reconhecimento das pretensões de validade só pode se dar sob o pressuposto de que elas possam ser resgatadas com razões se for o caso, o que significa satisfazer as condições de validade do ato de fala. Dependendo do aspecto de validade problematizado, pode-se instaurar, em termos tipológicos, um discurso teórico a respeito da verdade de proposições ou da eficácia de ações teleológicas, um discurso prático a respeito da correção de normas de ação, um crítica estética para a adequação ou autenticidade de padrões valorativos, uma crítica terapêutica para a veracidade de proferimentos expressivos (cf. HABERMAS, 1995b, p. 44 ss.).

É preciso observar que "discurso" e "crítica" são termos técnicos para designar formas de discussão argumentativa destinadas a resgatar pretensões de validade específicas. No entanto elas se diferenciam pelo fato de a "crítica" não poder cumprir todas as pressuposições pragmáticas identificadas em discursos habituais, como o teórico e o prático. A crítica 
terapêutica não pode evidentemente pressupor um pé de igualdade entre paciente e médico, o qual é uma pressuposição pragmática fundamental nos discursos teóricos e práticos. Por sua vez, a crítica estética não pode pressupor a possibilidade de alcançar um consenso universal a respeito de padrões valorativos, já que eles são sempre particulares, próprios de determinada cultura. Isso não significa que não se possa querer, digamos subjetivamente, pretender universalidade para eles ou para a exemplaridade de uma percepção estética, mas sim que as razões levantadas dificilmente podem justificar tais padrões valorativos para além de contextos locais. No entanto essa diferença entre "discurso" e "crítica", sustentada por Habermas nos anos setenta e oitenta, não impede, como veremos logo a seguir, a idéia de um "discurso ético", como variante de discursos sobre questões práticas, no qual estão em jogo valores que, à semelhança dos estéticos, são também sempre particulares.

É importante ainda observar que Habermas não apresenta, ao longo de sua obra, uma enumeração completa e definitiva dos pressupostos inevitáveis da argumentação. Nas "Notas programáticas para a fundamentação de uma ética do discurso", Habermas apela a uma sistematização de regras feita por Alexy, estabelecida conforme três planos distintos de pressupostos argumentativos. No plano lógico e semântico, esses pressupostos pragmáticos podem ser representados por regras que impedem a contradição e exigem a aplicação coerente de predicados e expressões. No plano procedimental, regras que garantem uma busca cooperativa da verdade, na qual cabe destaque a exigência de veracidade de cada afirmação dos participantes. No plano processual, regras que excluem todo tipo de coerção, externa ou interna, do processo de comunicação. As mais importantes estabelecem, nesse plano, que: todo sujeito capaz de falar e agir pode participar de discursos; cada um pode problematizar qualquer afirmação; cada um pode introduzir qualquer afirmação no discurso; cada um pode manifestar suas atitudes, desejos e necessidades; ninguém pode ser impedido de fazer valer estes direitos por coerção interna ou externa ao discurso (cf. HABERMAS, 1983, p. 99, trad. p. 110). Estas regras processuais asseguram, portanto, uma total inclusividade, liberdade e igualdade entre os participantes ${ }^{2}$.

Estas últimas regras possuem, portanto, um claro conteúdo normativo, do qual o princípio D é uma derivação imediata para a justificação de 
normas de ação, vale dizer, para a fundamentação da pretensão de validade da correção normativa. No entanto, elas são constitutivas também do discurso teórico e do explicativo-hermenêutico, e, de maneira nãointegral, da crítica estética e da terapêutica, ou seja, reiterando, não só para o discurso prático. Se o conteúdo normativo dos pressupostos argumentativos é interpretado como conteúdo moral, estabelecendo por si só um ponto de vista moral a assegurar a imparcialidade dos juízos práticos, então se teria por conseqüência que as resoluções argumentativas de pretensões de validade de verdade, de inteligibilidade, de veracidade e de autenticidade estética dependeriam, todas elas, direta e imediatamente desse ponto de vista moral.

Para medir a gravidade dessa conseqüência, é importante ter em vista a interligação da teoria das formas de argumentação com a teoria da modernidade cultural desenvolvida por Habermas. Seguindo Weber, Habermas concebe a modernidade cultural como marcada pela diferenciação do saber em diversas dimensões, ou no termo weberiano, em diversas esferas de valor, cada qual desenvolvida segunda uma legalidade específica. Na modernidade cultural, arte e crítica de arte, moral e discurso jurídico, ciência e saber tecnológico se caracterizam por seguirem leis próprias, independentes umas das outras, conforme as quais se desenvolvem de maneira autônoma questionamentos sobre gosto, justiça e verdade. Ora, desde um ponto de vista da teoria do discurso, Habermas converte as esferas de valor weberianas em esferas de validade, isto é, em esferas que consolidam formas de argumentação típicas para satisfazer distintas pretensões de validade, erguidas por diversos atos de fala. Assim, o que Habermas chama de discurso teórico, discurso prático e crítica estética, cada qual especializado respectivamente na pretensão de validade de verdade, de correção normativa e de autenticidade, apresenta o sentido interno da racionalização cultural nos princípios da modernidade. Essa estratégia teórica lhe permitirá garantir então uma unidade procedimental da razão, sem que cada esfera de validade seja submetida aos critérios de racionalidade de uma outra ${ }^{3}$.

Dessa maneira, se se compreende o conteúdo normativo dos pressupostos pragmáticos da argumentação como conteúdo moral, o resultado seria uma ingerência, por assim dizer, da moral em todas as formas de discurso e de crítica, isto é, uma ingerência da moral na ciência e na 
estética, para não falar, talvez, de uma subordinação destas àquela. Talvez se pudesse dizer que tal resultado representaria, tanto quanto em relação aos discursos de ordem prática, uma retomada de representações prémodernas, hierarquizando agora moral, ciência e arte. Daí que, na realidade, a neutralidade do discurso tem de ser atribuída não só às formas de discursos sobre questões práticas, mas a todas as formas de argumentação em geral (cf. DUTRA, 2005), caso se queira evitar uma ingerência de uma esfera de validade sobre outra.

Certamente, é preciso considerar que em relação à teoria do discurso proposta na Teoria da ação comunicativa, os desenvolvimentos posteriores a partir dos anos noventa introduzem uma diversificação que se poderia dizer interna ao discurso prático. Enquanto nos anos oitenta e mesmo antes o discurso prático é pensado paradigmaticamente como argumentação moral, posteriormente ele dá lugar a uma série de discursos sobre questões práticas. Mas disso não se pode concluir que se trata de uma modificação radical, como sugere Matthias Kettner, em relação à teoria do discurso em geral, como se tratasse de um afastamento em relação às primeiras abordagens (cf. KETTNER, 2002, p. 202). Trata-se antes de uma ampliação do quadro geral, em que o discurso prático-moral se vê agora acompanhado de um discurso pragmático e um ético-político. Pois, do contrário, na medida em que Facticidade e validade se refere apenas a essas formas discursivas, estaria sugerido também um abandono de tratamentos argumentativos para a dimensão estética, a expressiva e a hermenêutica, o que não nos parece sustentável.

\section{III}

Contudo aquela conseqüência para a teoria da modernidade tampouco pode decidir por si só a correta interpretação do conteúdo normativo dos pressupostos argumentativos. Pois, em sua formulação como regras processuais, eles parecem diferir muito pouco do conteúdo de mandamentos morais. Como diferenciar, por exemplo, uma regra pragmática que proíba qualquer coerção entre os participantes do discurso de um imperativo moral que proíba qualquer coerção entre seres humanos? A diferença parece dizer respeito apenas à extensão do campo de aplicação 
da regra. Enquanto regra moral, ela vale para todas as relações interpessoais, enquanto regra pragmática, apenas para relações estruturadas no interior do discurso.

No entanto, para Habermas, o que importa primeiramente é estabelecer a natureza das regras pragmáticas do discurso, à diferença das morais, e, em segundo lugar, como elas se vinculam ao que é discutido, isto é, as pretensões de validade problematizadas.

No primeiro aspecto, a diferença diz respeito ao caráter transcendental, em sentido fraco, das regras pragmáticas e o caráter deontológico das regras morais. As regras pragmáticas são as "condições de possibilidade" de todo discurso, na medida em que elas "têm" de ser pressupostas como suficientemente preenchidas atualmente, sem que se saiba, no entanto, que elas foram realmente preenchidas por todos os participantes. Dessa maneira, elas são idealizações inevitáveis e contrafactuais de práticas discursivas factuais, e por isso também só é possível contar com aproximações suficientes, diferentemente de uma constituição a priori em sentido forte. Sua validade normativa também se restringe apenas às praticas discursivas. $\mathrm{O}$ que tem de ser pressuposto e reciprocamente imputado a todos os participantes não significa por isso um "ter de" para a esfera da ação, para além da argumentação. Com isso, a normatividade efetiva no interior do discurso não se confunde com a validade deontológica de um mandamento moral, que obriga incondicionalmente também - e sobretudo, já que se trata de normas de ação - na esfera da ação social. "Mesmo se nós entendemos a igual distribuição de liberdades comunicativas e a condição de franqueza para um participante do discurso no sentido de direitos e deveres da argumentação, a obrigação fundamentada na pragmática transcendental não pode ser transferida imediatamente do discurso para a ação e não podem ser traduzida pela força deontológica, reguladora da ação, de direitos e deveres morais. (...) Também a pressuposição de ausência de coerção se refere apenas à constituição do próprio processo de argumentação, não às relações interpessoais fora dessa práxis" (HABERMAS, 2005, p. 90-1). Dessa maneira, a validade normativa das regras pragmáticas se diferencia também da validade axiológica de uma constelação de valores ou da eficácia empírica de uma regra técnica (cf. HABERMAS, 1994, p. 18). 
Dessa diferença entre a normatividade pragmática, entendida no sentido da pragmática transcendental, e a normatividade prática, no sentido da moral ou da ética, não se pode concluir, no entanto, que haveria a possibilidade de haver discursos inespecíficos, como que sem conteúdo. Não há argumentações sem questões específicas, um discurso puro que se diferenciaria posteriormente, uma espécie de metadiscurso, acima das formas do discurso teórico e do prático. Essa observação é importante também para afastar a impressão equivocada segundo a qual o princípio do discurso, situado em um nível de abstração e de neutralidade em relação à moral e ao direito, e também a todas outras formas de discurso prático, poderia se operar independentemente dessas formas ${ }^{4}$. Ou seja, embora os pressupostos pragmáticos da argumentação sejam os mesmos, e contenham uma mesma normatividade, é só por um ato de abstração analítica que eles podem ser separados das pretensões de validade, efetivamente discutidas.

Tais pressupostos pragmáticos têm de ser tomados, então, muito mais como potencial de racionalidade que fornece critérios imanentes às práticas discursivas, de modo a permitir um processo interno de aprendizagem, na medida em que permitem correções e críticas aos resultados dessas práticas (cf. HABERMAS, 2005, p. 91). Esse potencial de racionalidade se desdobra em direções distintas conforme as pretensões de validade envolvidas e conforme o saber específico sobre o que precisa ser levado em conta para a resolução de controvérsias a respeito de cada pretensão de validade.

Ao se tratar de pretensões de verdade, os participantes do discurso teórico não podem apenas contar com uma aproximação suficiente em relação às condições que garantem uma assertibilidade ideal, isto é, às idealizações pragmáticas da argumentação. A justificação da verdade de um enunciado que descreve algo no mundo objetivo não pode depender apenas da satisfação das regras pragmáticas. Se estas devem assegurar uma aceitabilidade racional dos argumentos em jogo, os próprios argumentos não podem ser considerados válidos de uma vez por todas, ou seja, infalíveis. Os próprios processos de aprendizagem no interior de discursos teóricos se consolidam no saber dos participantes sobre a diferença entre a justificação ideal de uma pretensão de verdade e a própria verdade de um enunciado. Consensos obtidos em discursos considerados 
racionais podem se revelar falsos, quando o conhecimento do mundo objetivo progrediu, mostrando que as razões antes consideradas as melhores dependiam de uma situação epistêmica já superada. Assim, não se pode afirmar nenhum "nexo conceitual entre verdade e assertibilidade racional sob condições ideais" (HABERMAS, 1999, p. 50)5 . Ou seja, a justificação da verdade de um enunciado descritivo sempre dependerá de uma referência ao mundo objetivo como tal, suposto como idêntico para todos, e que transcende o plano do discurso. Por outro lado, as condições idealizantes que garantem a aceitabilidade racional forçam também à busca de uma situação epistêmica cada vez melhor, na medida em que reclama uma adoção recíproca de perspectivas de interpretação do mundo, e com isso, a uma descentração progressiva dessas perspectivas. É nesse sentido que o potencial de racionalidade se desdobra no interior de discursos teóricos.

Quando se trata de pretensões de caráter normativa ou regulativo, ou seja, de discursos sobre questões práticas, esse potencial de racionalidade é orientado para um outro sentido. No caso dos discursos morais, as condições da aceitabilidade racional se confundem inteiramente com as condições de fundamentação de normas de ação. Ou seja, a validade moral não depende de um ponto de referência que transcenda o próprio discurso, como é o caso das descrições supostamente verdadeiras do mundo objetivo. Mas com isso o conteúdo normativo que, no discurso teórico, serve de critério para uma avaliação imparcial de interpretações do mundo, se tornam exigências para uma consideração simétrica dos interesses práticos de todos os envolvidos. $\mathrm{O}$ fato de que a validade de normas morais afeta diretamente os envolvidos no discurso transforma o sentido da práxis argumentativa por inteiro. "A pressuposição inocente de ponderação franca e imparcial de todos os argumentos força os participantes de discursos práticos a lidar de maneira autocrítica com as próprias carências e avaliações da situação e a considerar a constelação de interesses dos outros desde as perspectivas de compreensões do mundo e de si mesmo alheias" (HABERMAS, 2005, p. 94). Ou seja, o próprio conteúdo das discussões, a pretensão de verdade de um enunciado descritivo em um caso, a pretensão de correção de uma norma moral em outro, implica efetividades diferentes das regras argumentativas, que, no entanto, são as mesmas nos dois casos. A noção de imparcialidade por 
assim dizer teórica se converte em uma noção de imparcialidade prática tão logo se trate de uma norma que tem conseqüências para os envolvidos também no plano da ação. E isso porque cada resolução argumentativa envolve um saber preliminar sobre o que significa argumentar a favor da verdade de um enunciado, de um lado, e sobre o que significa ter obrigações e justificar moralmente ações, de outro. Esse saber não é dado com as regras da argumentação, ele já está associado ao sentido da validade de normas morais, modificando o sentido do potencial de racionalidade destas regras. "O saber sobre como participar de uma práxis argumentativa tem de se vincular a um conhecimento nutrido pelas experiências vitais de uma comunidade moral. Que nós temos de estar familiarizados com a validade deontológica de mandamentos morais e com a fundamentação de normas se torna evidente quando consideramos a genealogia dos desafios aos quais a moral da razão apresentou a resposta" (HABERMAS, 2005, p. 194).

Não é preciso aqui fazer a reconstituição precisa dessa genealogia do saber moral (cf. HABERMAS, 1998, p. 11 ss). A idéia básica consiste em explicar como seria possível manter na modernidade, em um momento da história ocidental marcada por um pluralismo de visões de mundo de diversos tipos, o teor cognitivo dos mandamentos morais, isto é, sua capacidade de ser fundamentados em sua validade universal, em analogia com a capacidade de se fundamentar universalmente a verdade de enunciados descritivos. Na tradição judaico-cristã - mas não só nela -, tal teor cognitivo é sustentado teológica e metafísicamente. Na tradição judaicocristã, os mandamentos morais deviam seu teor cognitivo ao fato de ser interpretados como mandamentos de um Deus ao mesmo tempo onisciente e absolutamente justo e bondoso. Somente a partir desses dois traços teológicos, um relativo à ordem da criação e outro à ordem da salvação, seria possível justificar o mandamentos divinos como dignos de reconhecimento, e isso para todos os membros da comunidade religiosa, de modo obrigatório. Porém, os mandamentos morais se confundem, nessa visão teológica do mundo, com valores éticos, configurados em uma conduta exemplar querida por Deus, e também em relações solidárias com os membros da comunidade religiosa. Por outro lado, a idéia de um julgamento final a respeito da conduta do indivíduo implica o reconhecimento de seu caráter insubstituível, o que nas relações inter- 
subjetivas se estrutura como exigência mútua de justiça, isto é, do respeito ao outro em sua alteridade. Tanto o aspecto da solidariedade quanto o da justiça são integrados entre si e definem a substância normativa dos mandamentos morais e de sua justificação, embora estes, enquanto tais, dependam ainda das representações teológica-metafísicas.

Os desafios próprios da modernidade consistiriam, então, em como dar continuidade a um processo de aprendizagem moral a respeito dessa substância normativa, o qual foi iniciado e determinado pela ou no interior das visões religiosas do mundo. Ou seja, em um contexto em que os argumentos teológicos e metafísicos bem como valores éticos impregnados religiosamente perdem sua validade publicamente, ainda que possam continuar a orientar os indivíduos e os diversos grupos privadamente. $\mathrm{O}$ que significa agir moralmente e fundamentar normas morais é, portanto, um saber que já estava inscrito nas relações intersubjetivas de uma comunidade moral-religiosa, mas agora esse conhecimento precisa buscar, em sociedades plurais, um princípio não-religioso, pós-tradicional, que faça jus aos princípios de justiça e solidariedade. Como não resta nada mais que a discussão entre indivíduos e grupos cujas concepções de bem são radicalmente distintas, a resposta moral a respeito do que é bom e obrigatório para todos terá que depender unicamente das propriedades formais dessa mesma discussão argumentativa. "Sem o recurso à sua familiaridade prévia com relações de reconhecimento intactas, sustentadas por tradições 'fortes', da comunidade moral à qual eles pertenceram sob condições de vida pré-modernas, os concernidos nem sequer poderiam conceber o propósito de reconstruir uma moral pós-tradicional somente a partir das fontes da razão comunicativa" (HABERMAS, 2005, p. 95).

Dessa linha de raciocínio decorre, então, a importância de saber o que está em jogo na argumentação, pois esse conteúdo redireciona em cada caso a normatividade pragmática do discurso, aproveitando-a para fundamentação específica. A mesma linha de raciocínio se estende para os demais discursos de natureza prática, pois se as normas morais trazem como que por si mesmas um saber sobre o seu sentido deontológico e sobre as condições de sua justificação, o mesmo poderá ser dito de normas éticas e de regras pragmáticas. Ou seja, é decisivo saber que normas de ação se trata. 
Porque o conteúdo normativo da argumentação, em especial a exigência de imparcialidade, ganha sentidos diferentes em cada caso, ele pode ser expresso, para discursos práticos em geral, no princípio D, como princípio de uma formação imparcial de juízos práticos. Certamente, a imparcialidade exigida nesse gênero de discursos já é interpretada diferentemente daquela exigida no interior de discursos teóricos devido à própria matéria de discussão, ou seja, normas de ação. Porém ele ainda pode ser considerado praticamente neutro, na medida em que não são dadas as diferenças dos discursos práticos, que se impõem com a especificação das normas de ação, isto é, se são de natureza moral, ética-política, pragmática (no sentido de ações teleológicas) ou jurídica. No entanto, cabe perguntar se essa reorientação do potencial de racionalidade dos pressupostos argumentativos já não é de saída de natureza moral, isto é, se o sentido da imparcialidade não se confundiria com o sentido da justiça moral, reclamando um respeito igual por cada um e uma consideração igual pelos interesses de todos. Com isso, retornamos à questão inicial sobre a pretensa neutralidade do princípio $\mathrm{D}$, sem que, aparentemente, tenhamos ganhado muita coisa com a idéia de redirecionamentos do potencial de racionalidade embutido em todos os discursos e com a distinção entre o sentido transcendental e deontológico de normatividade, a não ser, talvez, a diferença entre a imparcialidade "teórica" e a "prática”, em geral.

A questão que teria de ser colocada seria então em que a imparcialidade exigida por $\mathrm{D}$ difere da justiça moral, tendo em vista suas possíveis operacionalizações para questões ético-políticas e pragmáticas, e para o direito, segundo um princípio de democracia que leva em conta todos os questionamentos na fundamentação de normas jurídicas. Vejamos então, primeiramente, como se constituem essas formas de discurso prático.

Habermas distingue, no contexto da análise da formação política racional da vontade (cf. HABERMAS, 1994, p. 195 ss), discursos pragmáticos, ético-políticos, morais e jurídicos, além de negociações reguladas por procedimentos, conforme a natureza dos questionamentos suscitados na esfera pública. Esses discursos podem se situar em dois níveis distintos, um de fundamentação das normas e outro de aplicação. Essa última 
distinção não nos interessa aqui, já que se trata de buscar discernir a neutralidade do princípio D para as formas de discursos que são pressupostas para a fundamentação legítima de normas jurídicas, ou seja, os discursos pragmáticos, ético-políticos e morais. Para a análise dos discursos jurídicos seria preciso levar em conta também a forma direito e discursos de aplicação nas práticas de decisão judicial.

Questões pragmáticas são aquelas que surgem a respeito dos melhores meios para a realização de fins dados e preferências. Geralmente fins e preferências são dados conforme orientações axiológicas compartilhadas pelos atores. O que está em jogo é a escolha racional entre diversas alternativas de ação, a qual se baseia em um saber empírico sobre técnicas e estratégias. Ele possibilita instruções sobre ações que se consolidam em imperativos condicionados, do tipo se p então q. De modo geral, pode-se dizer que se trata aqui da fundamentação de regras para a ação instrumental, na qual se colocam pretensões de verdade sobre a melhor descrição do estado de coisas mas sobretudo de pretensões de eficácia sobre a melhor escolha de meios para fins dados. No entanto, apesar de sua racionalidade eminentemente teleológica e cognitiva, essas questões podem ter relevância prática na medida em que se trata de fundamentar a realização de programas políticos e finalidades coletivas, cuja realização envolve diversas possibilidades de ação.

Questões ético-políticas dizem respeito à pergunta "o que devemos fazer" quando as orientações axiológicas se tornam problemáticas e demandam um auto-esclarecimento do grupo a respeito de sua identidade coletiva, estruturada em uma forma de vida. O auto-esclarecimento sobre a autenticidade de uma identidade, que já pode ser desenvolvida em termos individuais em discursos ético-existenciais, ganha assim contornos ético-políticos. Os próprios valores coletivos, que definem de antemão finalidades e programas políticos, são questionados, portanto, a partir de sua autenticidade no que se refere às tradições e formas de vida que definiam a identidade do grupo. Dessa maneira, os discursos ético-políticos procuram reconstituir formas de vida a fim de encontrar uma resposta sobre o que é "bom para nós", e somente nesse sentido deve ser interpretado o "dever ser" ético.

Questões morais surgem quando se trata de solucionar conflitos entre orientações axiológicas não a partir de uma autocompreensão esclareci- 
da de uma identidade prévia, mas sim a partir de um princípio que possibilite a resposta sobre o que é igualmente bom para todos. O que importa nesse caso é o aspecto da justiça, o respeito igual por cada um e a consideração simétrica dos interesses de todos, para além da esfera de uma comunidade concreta. A justiça de uma norma só pode ser assegurada quando todos podem querer que ela seja seguida por qualquer um em situações semelhantes. O dever-ser moral se incorpora assim em imperativos categóricos, absolutamente incondicionais. Os discursos morais, voltados para a resolução dessas questões, se caracterizam então por um princípio de universalização que pode testar quaisquer normas de ação ou interesses expressos nelas podem ser generalizados e aceitos por todos, em vista de uma observância geral por todos.

Toda essa tipologia só parece ser possível na medida em que o princípio do discurso é normativamente neutro, e isso não só no que diz respeito à moral e o direito, mas também no que diz respeito à ética e a argumentos pragmáticos, de modo que ele pode se especificar e operacionalizar para as respectivas argumentações (cf. HABERMAS, 1994, p. 140). Em seu nível de abstração, no entanto, o princípio D só expressa a garantia de um consenso não-coercitivo, e essa garantia é dada pela exigência de imparcialidade na formação do juízo prático. Se essa imparcialidade tivesse por si só um teor moral, os discursos pragmáticos e éticopolíticos já deveriam estar submetidos desde o começo à lógica do questionamento moral. Como não parece ser este o caso, como interpretar tal imparcialidade e sua recolocação segundo cada questionamento?

Mathias Kettner propõe a seguinte solução para o problema: "Imparcialidade é somente uma condição necessária, não uma condição suficiente de agir moralmente (...) É um equívoco equacionar imparcialidade com justiça ou eqüidade. Leis injustas e justas podem ser administradas imparcialmente, e normas de ação obtidas em deliberações imparciais podem ser moralmente ultrajantes em todos os aspectos" (KETTNER, 2002, p. 209). As demais condições para a ação moral seriam justamente o igual respeito por cada um e a consideração igual pelos interesses de todos. Só reunindo a imparcialidade com essas condições poderia se constituir o ponto de vista moral. Conseqüentemente, seria possível um juízo pragmático, formado imparcialmente, sobre a validade de roubar comida do vizinho em tempos dificeis, como o melhor meio 
para a sobrevivência. Em um discurso moral, no entanto, essa recomendação pragmática seria considerada totalmente injusta.

No entanto Kettner entende por imparcialidade uma noção "standard”, caracterizada pela exclusão de considerações sobre benefícios ou prejuízos para qualquer participante de discursos racionais. Dificilmente é nessa acepção que Habermas toma a imparcialidade do princípio do discurso, tão logo observamos sua derivação das regras da argumentação em geral. A imparcialidade tem nesse caso, de modo geral, o sentido de garantir uma máxima reciprocidade de pontos de vistas para a obtenção de um consenso não-coagido. Com isso, ela já está ligada a algo como o "respeito" por cada um e, mais ainda, à "igual consideração" pelos interesses ou perspectivas de todos. O que muda, em cada discurso, é o sentido dado a essas condições de reciprocidade, que, como condição de comunicação em geral, só se destina a garantir todas as contribuições relevantes e os posicionamentos sobre pretensões de validade.

No caso dos discursos teóricos sobre pretensões de verdade, a imparcialidade impõe, como vimos, uma descentração de perspectivas epistêmicas, o qual só é possível por um certo respeito e por uma certa consideração simétrica de perspectivas, mas isso não no sentido de uma exigência moral, mas como condição para um exame sobre a aceitabilidade racional de afirmações. Não é preciso respeitar moralmente o outro em sua dignidade como ser humano para considerar sua perspectiva sobre a validade de um enunciado descritivo. Nos discursos pragmáticos, cuja racionalidade se assemelha, até certo ponto, aos discursos sobre verdade, o que é decisivo continuam sendo as contribuições sobre o saber empírico em que se baseiam regras técnicas e estratégicas. Na avaliação de qual é o melhor meio para a realização de fins já justificados moral ou eticamente, cabe discernir a pretensão de eficácia à luz de conseqüências queridas ou rejeitadas. Para isso é preciso considerar os pontos de vista dos envolvidos imediatamente na discussão, sem que isso se fundamente moralmente em termos de justiça. Embora a realização de programas políticos tenha como contexto uma esfera de relações intersubjetivas, da perspectiva da eficácia ela é objetivada como se fosse um mundo objetivo, da mesma maneira que acontece na discussão sobre pretensões de verdade. A pretensão de correção normativa não se coloca na lógica da argumentação pragmática, de modo que o pressuposto da imparcialidade e da 
adoção recíproca de perspectivas não vão além do sentido de uma condição para a melhor argumentação sobre a escolha de meios mais ou menos eficazes.

As coisas parecem se complicar quando se trata de discursos éticopolíticos, cuja relevância é maior do que os pragmáticos para a formação política racional da vontade. Em que medida a discussão sobre valores concretos que determinam uma identidade coletiva pode ser encaminhada por um princípio de imparcialidade puramente discursiva, não-moral? Embora não se encontre nos textos de Habermas uma explicação de como o princípio do discurso se operacionaliza nos discursos éticopolíticos, é possível concluir do que foi exposto que a imparcialidade e suas condições de reciprocidade visam apenas a garantir uma melhor interpretação, uma melhor reflexão, quase de natureza clínica (cf. HABERMAS, 1994, p. 202), sobre a identidade de um grupo formada com base em orientações axiológicas. Se em discursos ético-políticos o que está em jogo é a realização apropriada de uma idéia de bem coletivo, o quadro de referência é sempre uma comunidade concreta, que pode ser designada nos termos de uma primeira pessoa do plural: nós. Nesse aspecto, tudo se passa como se o mundo social da comunidade se convertesse em um mundo subjetivo singular, o qual reflete sobre sua história de formação a fim de preservar os meios da auto-realização ética. Certamente, pode-se considerar que o respeito pelo outro e a consideração por todos os membros do grupo ganha uma coloração normativa diferente daquela meramente discursiva. Em todo caso, essa coloração não vai além das referências axiológicas concretas, já que o outro é visto de antemão, segundo a lógica do questionamento ético, como um membro de uma mesma e única comunidade. Em última instância, a imparcialidade e a reciprocidade impostas pelo discurso só podem operar aqui como condição da melhor reflexão sobre valores e sobre as tomadas de posição sobre os conselhos derivados dessa reflexão.

É somente nos discursos morais que, como vimos acima, as condições da comunicação livre se transformam inteiramente, deixando de ser apenas condições garantidoras de um livre intercâmbio de argumentos para se converter também em critérios de justiça. O respeito ao outro e a consideração simétrica de perspectivas se converte em exigências também morais, isto é, dotadas de um aspecto deontológico. Mas isso já em uma 
etapa lógica em que o princípio D se operacionaliza como uma regra de argumentação, como um princípio de universalização (U) que toma como pedra de toque o respeito igual do outro e a consideração igual dos interesses de todos. Chama a atenção que é só no nível dos discursos morais que ganha inteireza a referência a um mundo social compartilhado por pessoas inteiramente distintas. É somente na relação com um outro visto em sua alteridade completa, e não como parceiro de uma realização pragmática de fins, ou como co-integrante de uma coletividade ética, que faz sentido colocar questões de justiça. Esse discernimento, no entanto, não pode ser desencadeado por si só pela racionalidade discursiva, ele tem de pressupor conhecimentos prévios sobre o que significa agir de maneira justa. Por outro lado, em condições de vida moderna, pós-tradicional, o que pode decidir sobre questões de justiça dependerá do aproveitamento das estruturas formais do discurso.

Em suma, o princípio D expressa o sentido da imparcialidade de juízos práticos de modo geral, mas se condiciona de maneira diferente dependendo do conteúdo desses juízos. No caso dos discursos pragmáticos, ele garante um melhor discernimento sobre eficácia, no caso dos ético-políticos, uma melhor interpretação sobre valores e identidades coletivas, mas só no caso dos morais, um ponto de vista sobre o justo.

1 No que segue é preciso ter cuidado com a expressão "pragmático", já que ela pode se referir tanto ao sentido da realização de fins, como aos pressupostos comunicativos do discurso.

2 Em relação aos três planos da argumentação, convém observar que, apesar da distinção entre procedimento e processo, o primeiro termo possui também uma acepção mais geral, de modo a incluir todos os pressupostos pragmáticos que constituem as formas de argumentação.

3 A respeito do tema da unidade da razão em Habermas, cf. TERRA, 2003, REPA, 2006 e SEEL, 1986.

${ }^{4}$ Teubner parece ter essa impressão: "Embora o princípio do discurso seja abstrato demais para resolver questões práticas, ao menos, em um meta-nível, ele pode desenvolver procedimentos e critérios capazes de ser universalizados para resolver conflitos de jurisdição entre discursos morais, jurídicos e políticos." (TEUBNER, 1998, p. 178, grifo meu). Nesse sentido, Teubner fala de uma simpatia de Habermas por um "superdiscurso filosófico" estabelecendo juridições e compatibilidades para as diferentes formas de discursos.

5 O reconhecimento dessa diferença representa um afastamento de Habermas de sua primeira concepção da verdade como consenso, defendida em “Teorias da verdade”, na qual a verdade 
se definia pelo consenso obtido em um contexto de justificação sob condições ideais. Cf. HABERMAS, 1995a, p. 127 ss).

\section{Referências bibliográficas}

APEL, K-O. 1998. “Auflösung der Diskursethik? Zur Architektonik der Diskurs-differenzierung in Habermas' Fakzität und Geltung (Dritter Verscuh, mit Habermas gegen Habermas zu denken). In: Auseinandersetzungen. Frankfurt am Main: Suhrkamp.

DUTRA, D. J.V. 2005. Razão e consenso em Habermas. A teoria discursiva da verdade, da moral, do direito e da biotecnologia. Florianópolis: Editora da UFSC.

HABERMAS, J. 1983. Moralbewußtsein und kommunikatives Handeln. Frankfurt am Main: Suhrkamp (trad. Consciência moral e agir comunicativo. Rio de Janeiro: Tempo Brasileiro, 1989). .1994. Faktizität und Geltung. Frankfurt am Main: Suhrkamp. . 1995a. "Theorien der Wahrheit". In: Vorstudien und Ergänzungen zur Theorie des kommunikativen Handelns. Frankfurt am Main: Suhrkamp. 1995b. Theorie des kommunikativen Handelns, vol I. Frankfurt am Main: Suhrkamp. .1995c. "Was heisst Universalpragmatik?". In: Vorstudien und Ergänzungen zur Theorie des kommunikativen Handelns. Frankfurt am Main: Suhrkamp.

. 1998. "Eine genealogische Betrachtung zum kognitiven Gehalt der Moral". In: Die Einbeziehung des Anderen, Frankfurt am Main: Suhrkamp. 1999. Wahrheit und Rechtfertigung. Franfkurt am Main: Suhrkamp. .2005. "Zur Architektonik der Diskursdifferenzierung. Kleine Replik auf eine grosse Auseinandersetzung”. In: Zwischen Naturalismus und Religion. Frankfurt am Main: Suhrkamp. 
KETTNER, M. 2002. "The Disappearance of Discourse Ethics in Habermas's Between Facts and Norms". In: Schomberg, R., Baynes, K. (org.) Discourse and democracy. Essays on Habermas's Between Facts and Norms. State University of New York Press.

REPA, L. 2006 ."A unidade da razão em Jürgen Habermas”. In: Peres, D. T. (org), Justiça, virtude e democracia. Salvador: Quarteto, 2006.

SEEL, M., 1986. “Die zwei Bedeutungen 'kommunikativer' Rationalität'. Bemerkungen zu Habermas' Kritik der pluralen Vernunft”. In: Honneth, A. e Joas, H. (org.), Kommunikatives Handeln. Frankfurt am Main: Suhrkamp.

TERRA, R. 2003. "Notas introdutórias sobre sistema e modernidade: Kant e Habermas”. In: Passagens: estudos sobre a filosofia de Kant. Rio de Janeiro: Editora UFRJ.

TEUBNER, G. 1998. "De Collisione Discursumm. Communicative Rationalities in Law, Morality, and Politics". In: Rosenfeld, M., Arato, A. Habermas on Law and Democracy. University of California Press. 